Discussion

Papers

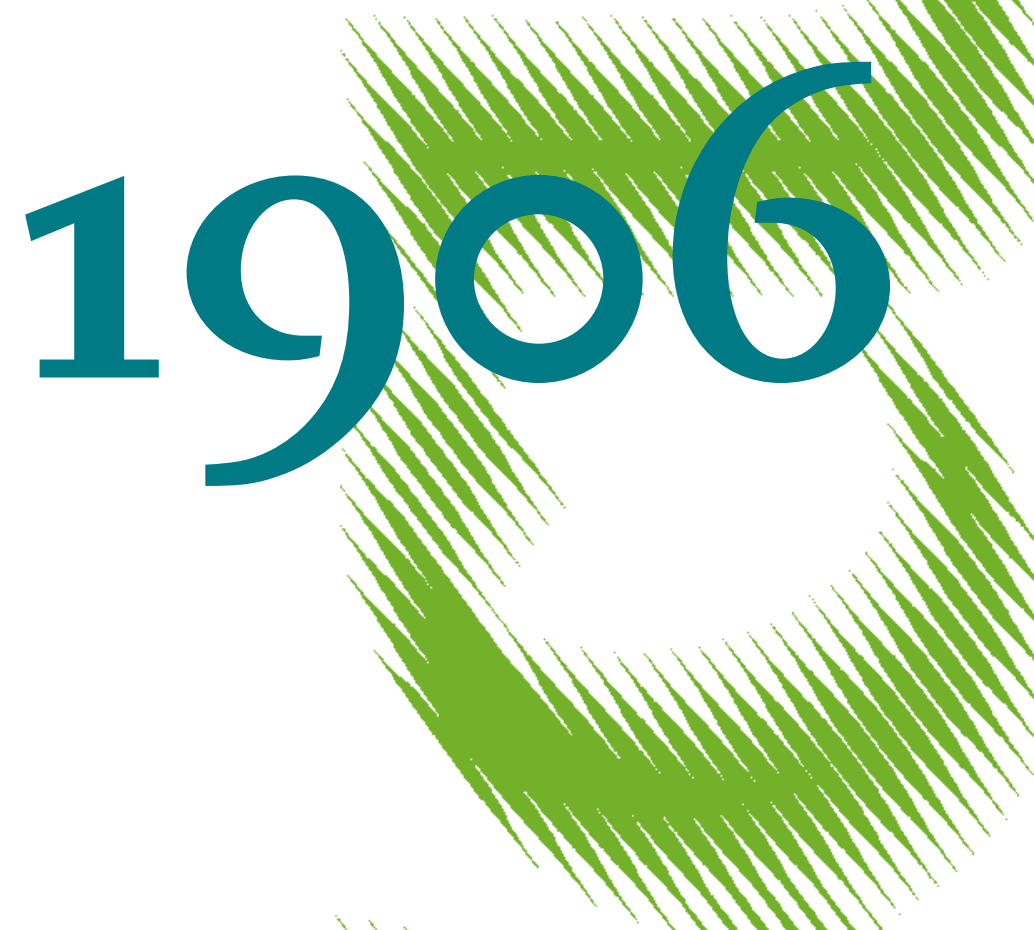

Exchange Rates and the Information Channel of Monetary Policy 
Opinions expressed in this paper are those of the author(s) and do not necessarily reflect views of the institute.

IMPRESSUM

(C) DIW Berlin, 2020

DIW Berlin

German Institute for Economic Research

Mohrenstr. 58

10117 Berlin

Tel. +49 (30) $89789-0$

Fax +49 (30) $89789-200$

http://www.diw.de

ISSN electronic edition 1619-4535

Papers can be downloaded free of charge from the DIW Berlin website:

http://www.diw.de/discussionpapers

Discussion Papers of DIW Berlin are indexed in RePEc and SSRN:

http://ideas.repec.org/s/diw/diwwpp.html

http://www.ssrn.com/link/DIW-Berlin-German-Inst-Econ-Res.html 


\title{
Exchange Rates and the Information Channel of Monetary Policy*
}

\author{
Oliver Holtemöller ${ }^{\dagger} \quad$ Alexander Kriwoluzky Boreum Kwak $^{\ddagger}$
}

October 13, 2020

\begin{abstract}
We disentangle the effects of monetary policy announcements on real economic variables into an interest rate shock component and a central bank information shock component. We identify both components using changes in interest rate futures and in exchange rates around monetary policy announcements. While the volatility of interest rate surprises declines around the Great Recession, the volatility of exchange rate changes increases. Making use of this heteroskedasticity, we estimate that a contractionary interest rate shock appreciates the dollar, increases the excess bond premium, and leads to a decline in prices and output, while a positive information shock appreciates the dollar, decreases prices and the excess bond premium, and increases output.
\end{abstract}

\section{JEL Classification: C36, E52, E58}

Keywords: Monetary policy, central bank information shock, identification through heteroskedasticity, high-frequency identification, proxy SVAR.

${ }^{*}$ We would like to thank Yoosoon Chang, Marek Jarociński, Jihyun Kim, Eric M. Leeper, Malte Reith, and the participants at CFE-CMStatistics 2018, the IWH-CIREQ-GW Macroeconometric Workshop 2018, the International Symposium on Econometric Theory and Applications 2019, the Verein fuer Socialpolitik-Annual Conference 2019, the Indiana University Alumni Workshop, and the IWH internal seminar for their helpful comments and discussions. We acknowledge financial support from Deutsch Bundesbank Grant No. 4/5-17.

${ }^{\dagger}$ Martin Luther University Halle-Wittenberg and Halle Institute for Economic Research (IWH)

${ }^{\ddagger}$ Freie Universität Berlin and German Institute for Economic Research (DIW Berlin)

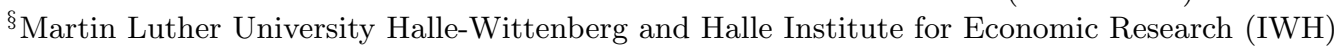




\section{Introduction}

How does monetary policy affect the economy? To answer this question, it is necessary to separate expected monetary policy decisions from news about monetary policy. Expected monetary policy actions, which are triggered by economic development, are endogenous and therefore cannot be used to identify the impacts of monetary policy on the economy. Therefore, researchers have used movements in interest rate futures in a narrow window around announcements by monetary authorities as an indicator for unexpected monetary policy surprises. However, recent research (Melosi, 2016; Campbell et al., 2016; Nakamura and Steinsson, 2018; Cieslak and Schrimpf, 2019; Miranda-Agrippino and Ricco, 2020; Jarociński and Karadi, 2020; Gürkaynak et al., 2020) points out that in the statement of a central bank after a monetary policy decision, the central bank not only communicates its decision but also provides an economic outlook. Thus, monetary policy affects the economy not only through the sheer unexpected change in interest rates but also by conveying information about the current and future state of the economy. For instance, increases in interest rates increase the opportunity cost of spending today and may therefore dampen current economic activity. This is called the interest rate channel of monetary policy. At the same time, if the monetary tightening is motivated by a rosy outlook for the economy, it could raise income and profit expectations and therefore stimulate private consumption and investment. This is the recently established central bank information channel. Since the announcement of a change in monetary policy rate and the accompanying outlook happen simultaneously, the effects of the change in monetary policy rate and of the central bank's private information on the economy are difficult to disentangle.

In this paper, we identify the interest rate channel and information channel using not only changes in interest rate futures but also changes in exchange rates around monetary policy announcements. Figure 1 shows the interest rate surprises (left panel) and changes in the effective exchange rate (right panel) around announcement dates for the US. We exploit the change in volatility of both variables that occurred at the beginning of the Great Recession in 2008. While the variance in the interest rate change is lower after the crisis, the variance in the exchange rate change is higher. We follow Nakamura and Steinsson (2018); Jarociński and Karadi (2020); Miranda-Agrippino and Ricco (2020) and assume that the changes in interest rate futures around Federal Open Market Committee (FOMC) announcements are driven by two components: the interest rate shock and information shock components. We make the same assumption for the changes in the exchange rate around FOMC announcements. Following Rigobon (2003), the heteroskedasticity of the changes in both variables allows us to identify interest rate shocks and information shocks on announcement dates.

The following example further illustrates why we consider the change in exchange rates that is especially susceptible to news about the economy. For example, on June 26th, 2002, the FOMC stated the following: "The Federal Open Market Committee decided today to keep its target for the federal funds rate unchanged at $13 / 4$ percent ... The Committee expects the rate of increase in 
Figure 1: Changes in interest rate futures and exchange rates around monetary policy announcements
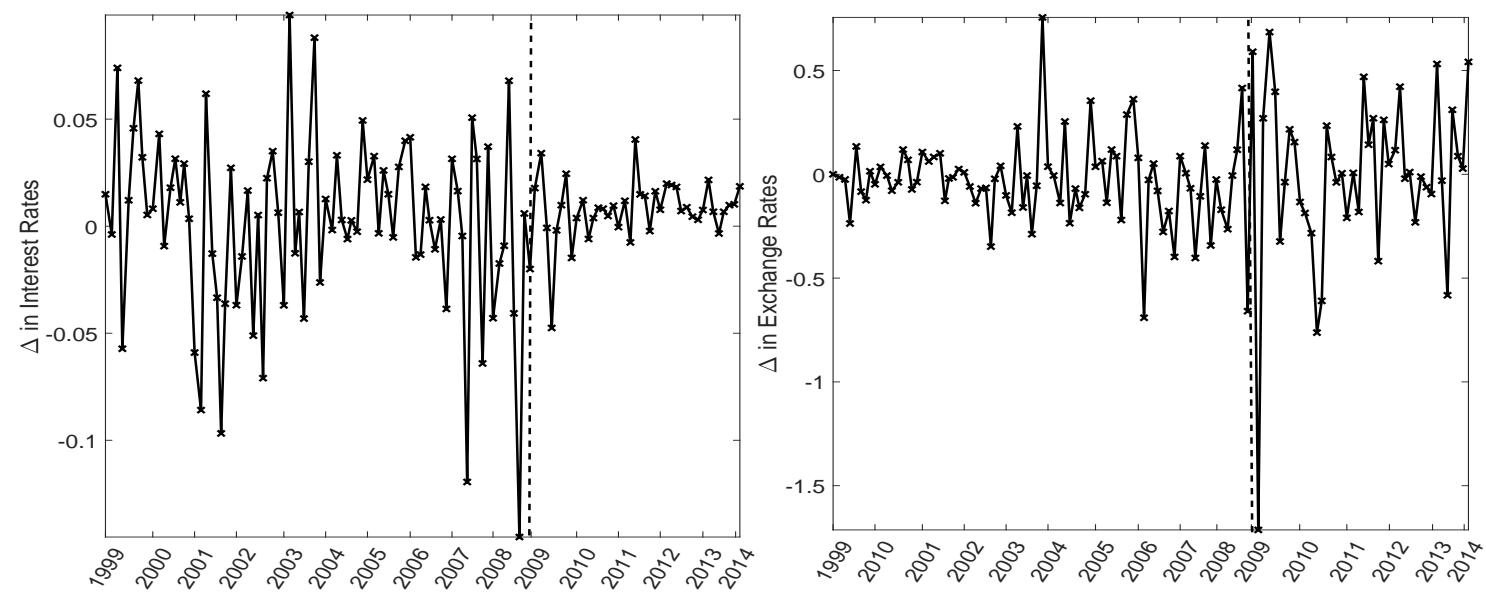

Notes: The left plot shows changes in interest rate futures around FOMC announcements obtained from Nakamura and Steinsson (2018), and the right plot shows the changes in the effective exchange rate calculated by the authors. The vertical dashed line for each plot denotes the December 2008 meeting.

final demand to pick up over the coming quarters, supported in part by robust underlying growth in productivity, but the degree of the strengthening remains uncertain..." The statement includes no change in the target rate and some positive statements about the economic condition but with uncertainty regarding the strength of economic growth. On this day, the US dollar depreciated around the announcement, while the change in interest rates was almost zero. We also identify a negative central bank information shock. The statement, although positive in nature, was more pessimistic than what the markets initially expected. This example is supported by Rosa (2011), who finds that the exchange rate is especially sensitive to the central bank's words compared to the actions embedded in policy announcements.

After we have disentangled the central bank information shock from the interest rate shock, we estimate the effects of both shocks on the economy. To accomplish this, we estimate a vector autoregression (VAR) model that contains the effective exchange rate, industrial production, the consumer price index (CPI), the excess bond premium (EBP), and the one- and the five-year government bond interest rates. To isolate the effects of both shocks, we employ them as proxy variables in a structural VAR model. ${ }^{1}$ We find that a contractionary monetary policy interest rate shock, which leads to an appreciation of the dollar, causes decreases in industrial production and the consumer price index. A positive information shock, which causes the dollar to appreciate, leads to an increase in industrial production and to a decrease in consumer prices. While the excess bond premium rises after a contractionary monetary policy interest rate shock, it falls after a positive information shock.

\footnotetext{
${ }^{1}$ For an overview of the econometric techniques used in our work, see Rossi (2019), which summarizes the econometric tools widely applied to identify monetary policy shocks during the zero-lower-bound (ZLB) period and estimate their effects on the economy.
} 
Our results corroborate the findings of Jarociński and Karadi (2020), Campbell et al. (2016), Miranda-Agrippino and Ricco (2020), and Bu et al. (2019) using a new identification strategy. Jarociński and Karadi (2020) combine the response of interest rate futures around a monetary policy announcement with the response of the stock market at the same time and impose a sign restriction to identify a monetary policy and central bank information shocks. They find a positive response of real GDP and a negative response of the excess bond premium to a positive information shock. Miranda-Agrippino and Ricco (2020) derive an informationally robust instrument for monetary policy interest rate shocks by accounting for informational rigidities and controlling for the information revealed in staff forecasts. Bu et al. (2019) decouple monetary policy and non-monetary policy shocks using Fama-MacBeth cross-sectional two-step regression. In addition to the above studies, Melosi (2016) identifies the information component in a monetary policy announcement by estimating a dynamic stochastic general equilibrium (DSGE) model. Jarociński (2019) employs a sign restriction to identify the central bank information shock and finds that there are considerable spillovers of Federal Reserve monetary information shocks on the Euro area. Gürkaynak et al. (2020) investigate the impact of central bank information on the behavior of exchange rates on policy dates. They show that a path shock defined as in Gürkaynak et al. (2005) significantly drives the exchange rate responses to monetary policy announcements and partially resolves the puzzling exchange rate responses based on a target shock.

Our paper is in the long tradition of identifying monetary policy innovations using highfrequency data on interest rate futures. The most recent examples include Nakamura and Steinsson (2018), Barakchian and Crowe (2013) and Gertler and Karadi (2015) who follow the work by Söderström (2001), Kuttner (2001), Cochrane and Piazzesi (2002), Faust et al. (2004), and Gürkaynak et al. (2005). Nakamura and Steinsson (2018) measure the change in interest rate futures of several maturities around monetary policy announcements and employ principal component analysis to extract the monetary policy shock that is named a "news shock". Andrade and Ferroni (2018) follow Gürkaynak et al. (2005) and identify a target and a path shock using a factor model for the innovations in interest rates along the yield curve around monetary policy announcements. They further employ sign restrictions and apply the concept of Campbell et al. (2012) to identify Delphic and Odyssean shocks in the path shock. Furthermore, our paper is related to recent papers that study the role of the exchange rate in the transmission of monetary policy: Faust et al. (2003), Glick and Leduc (2018), Neely (2015), Ferrari et al. (2017), Rogers et al. (2018), and Inoue and Rossi (2019).

We organize the remainder of this paper in the following way. Section 2 describes our identification strategy and the decoupled interest rate and information shocks. In Section 3, we establish a proxy VAR model to estimate the effects of both the interest rate and the information shocks on the economy, present the results, and conduct robustness checks. The final section concludes the paper. 


\section{Disentangling interest rate and information shocks}

In this section, we outline how we disentangle interest rate shocks from central bank information shocks. First, we measure the changes in exchange rates around the releases of FOMC statements. Second, we combine this measure with the interest rate shock series measured by Nakamura and Steinsson (2018).

\subsection{Exchange rates and monetary policy announcements}

We use the tick-by-tick high-frequency exchange rates for the U.S. dollar versus the Euro, the Canadian dollar, the British pound, the Swiss franc, the Japanese yen, the Australian dollar, and the Mexico peso covering the period from February 1, 1999, to April 31, 2014. ${ }^{2}$ The exchange rates are defined in foreign currency per U.S. dollar, i.e., a positive change implies an appreciation of the U.S. dollar. We measure the changes in the exchange rates within 30-minute windows (from 10 minutes before to 20 minutes after) around FOMC press releases. Then, we calculate the change in the effective U.S. exchange rate around FOMC announcements using the currency weights in the BIS narrow nominal effective exchange rate (NEER) index. The right panel in Figure 1 plots the high-frequency change of the effective exchange rate. It reflects the changes in the target rate and also the central bank's information on their future policy stance and the economic outlook. In the next section, we combine this time series with an interest rate shock time series to identify the interest rate shocks and the central bank information shocks.

\subsection{Identification through heteroskedasticity}

Our identification strategy is based on two key assumptions. First, changes in interest rate futures and exchange rates within a tight window around monetary policy announcements capture the interest rate shock and central bank information components as exogenous variations. Second, the variances in interest rate shocks and central bank information shocks changed around the start of the ZLB period. We provisionally call the component with a higher (smaller) volatility during the ZLB period the central bank information shock (interest rate shock). This assumption is supported by Cieslak and Schrimpf (2019), who analyze the information content of central bank communication and show that non-monetary news, which is the news related to economic growth and financial risk premia, composes a significant portion of communication events, e.g., FOMC statements. They also present empirical evidence that the portions of monetary policy and nonmonetary policy news embedded in communication events have changed over time; non-monetary news generated significant responses in financial variables during the recent financial crisis and in the early recovery before the interest rate shock regained its importance around mid-2013. ${ }^{3}$

\footnotetext{
${ }^{2}$ These currencies cover around $85 \%$ of the currency weights in the Bank for International Settlements (BIS) narrow exchange rate index. The high-frequency exchange rate data are obtained from Olsen Financial Technologies.

${ }^{3}$ Hoesch et al. (2020) study the effectiveness of the information channel by measuring the discrepancy between the responses to an informationally robust shock and to a non-robust shock for the subsample periods. Contrary to
} 
To identify interest rate shocks $\left(\epsilon_{t}\right)$ and central bank information shocks $\left(\eta_{t}\right)$, we consider the following model:

$$
\begin{aligned}
\Delta e x_{t} & =\epsilon_{t}+\eta_{t} \\
\Delta i_{t} & =\alpha \epsilon_{t}+\beta \eta_{t}
\end{aligned}
$$

where $\Delta i_{t}$ represents the changes in interest rate futures measured by Nakamura and Steinsson $(2018)^{4}$, and $\Delta e x_{t}$ denotes the changes in the effective exchange rate in 30-minute windows around FOMC announcements.

The magnitudes of the interest rate shocks and the central bank information shocks are normalized based on the scale of the changes in the exchange rates $\Delta e x_{t}$, and $\alpha$ and $\beta$ denote the weights on both shock components in the changes in the interest rate futures $\Delta i_{t}$. We assume that parameters $\alpha$ and $\beta$ are time-invariant. Under our model specification, changes in the volatility of $\Delta e x_{t}$ and $\Delta i_{t}$ are induced by changes in the volatility of the underlying shock components, $\epsilon_{t}$ and $\eta_{t}$.

To conduct identification through heteroskedasticity, we assume there are high and low volatility regimes in the underlying structural interest rate and information shocks and that both shocks are uncorrelated with each other. Furthermore, we hypothesize that the volatility changes are observed around the start of the ZLB period. We therefore test the hypothesis of the equality of the variances for the pre-ZLB and the ZLB periods. Table 1 presents the $F$-test results for the variances of $\Delta i_{t}$ and $\Delta e x_{t}$ in the subsamples. The test shows that the variances did indeed change. In addition to the baseline estimation, we exclude the peak of the financial crisis from July 2008 to August 2009 and repeat the analysis as a robustness check. The test results excluding the financial crisis observations are reported in parentheses in Table 1. For both cases, we reject the null hypothesis of the equality of variances for subsamples. ${ }^{5}$

Table 1: F-test for variances: pre-ZLB and ZLB

\begin{tabular}{c|cc||cc}
\hline & \multicolumn{2}{|c||}{$\Delta i_{t}$} & \multicolumn{2}{c}{$\Delta e x_{t}$} \\
\hline Period & Pre-ZLB & ZLB & Pre-ZLB & ZLB \\
\hline Variance & $0.0018(0.0016)$ & $0.0002(0.0002)$ & $0.043(0.037)$ & $0.16(0.09)$ \\
Obs. & $80(76)$ & $43(38)$ & $80(76)$ & $43(38)$ \\
\hline p-value & \multicolumn{2}{|c||}{$3.8 \mathrm{E}-12$} & $(1.7 \mathrm{E}-10)$ & $4.8 \mathrm{E}-8(7.3 \mathrm{E}-4)$ \\
\hline
\end{tabular}

Since the test indicates that the volatilities of the observed time series changed with the emergence of the ZLB, we follow Rigobon (2003) and assume there are two high and low volatility regimes in the interest rate shocks and the information shocks. As we assume that the structural parameters are stable across the regimes, the two reduced-form covariance matrices for each regime

Cieslak and Schrimpf (2019), they find that the importance of the information channel became weak after early 2000.

${ }^{4}$ The first principal component of the changes in interest rate futures, also known as the policy news shock in Nakamura and Steinsson (2018), is obtained from https://academic.oup.com/qje.

${ }^{5}$ By reflecting that the Federal Reserve set interest rates to between $0 \%$ and $0.25 \%$ on December 2008 , we consider December 2008 as the starting month of the ZLB period. 
$s \in\{1,2\}$ have the following structure:

$$
\Omega_{s}=\left(\begin{array}{cc}
\sigma_{\epsilon, s}^{2}+\sigma_{\eta, s}^{2} & \alpha \sigma_{\epsilon, s}^{2}+\beta \sigma_{\eta, s}^{2} \\
\cdot & \alpha^{2} \sigma_{\epsilon, s}^{2}+\beta^{2} \sigma_{\eta, s}^{2}
\end{array}\right)=\left(\begin{array}{cc}
A_{s} & B_{s} \\
\cdot & C_{s}
\end{array}\right),
$$

where the variances in the structural shocks in regime $s$ are given by $\sigma_{\epsilon, s}$ and $\sigma_{\eta, s}$, and where $\Omega_{s}$ indicates the (reduced-form) variance-covariance matrix in regime $s$. To achieve identification, when both variances changed, as shown in Table 1, the relative variances also need to be shifted to satisfy the rank condition, as discussed in Rigobon (2003). We observe that our two covariance matrices are not proportional, implying that $A_{1} B_{2}-A_{2} B_{1} \neq 0 .{ }^{6}$ There are six unknowns $\left(\alpha, \beta, \sigma_{\epsilon, 1}^{2}, \sigma_{\eta, 1}^{2}, \sigma_{\epsilon, 2}^{2}\right.$, and $\sigma_{\eta, 2}^{2}$ ) and two covariance matrices, which provide six equations; i.e., our model is exactly identified. With some algebra, we have

$$
B_{s}=\alpha A_{s}+\frac{1}{\alpha+\beta} C_{s}-\frac{\alpha^{2}}{\alpha+\beta} A_{s}, \quad s \in\{1,2\} .
$$

By plugging in $A_{s}$ and $B_{s}$ from the reduced-form covariance matrix $\Omega_{s}$, we obtain the values of $\alpha$ and $\beta$, respectively. From equations (1) and (2), we obtain $\epsilon_{t}$ and $\eta_{t}$, respectively, as follows:

$$
\epsilon_{t}=\frac{\beta \Delta e x_{t}-\Delta i_{t}}{\beta-\alpha}, \quad \eta_{t}=\frac{\alpha \Delta e x_{t}-\Delta i_{t}}{\alpha-\beta} .
$$

From our specification, the estimated $\epsilon_{t}$ and $\eta_{t}$ are orthogonal and identified up to scale. Figure 2 shows the estimated decoupled interest rate shocks and central bank information shocks.

It is worth noting that our disentangled interest rate and information shocks are robust to potential misspecified regime windows and an underspecified number of regimes. Rigobon (2003) shows the consistency of the identification using heteroskedasticity under mild misspecifications of the regime windows and the number of regimes of heteroskedasticity. However, assuming stable parameters across volatility regimes can in general be a source of misspecification. ${ }^{7}$ The constant coefficient assumption has been imposed widely in empirical applications using VAR models covering both pre-ZLB and ZLB periods. Sims and Zha (2006) consider a multivariate regime-switching model for monetary policy with U.S. data and show that the existence of time-varying volatility explains the U.S. data better, while any evidence of a change in the structural parameters is marginal. Swanson (2017) also shows that forward guidance has essentially the same effects on medium- and longer-term interest rates before and during the ZLB period in the U.S.

\footnotetext{
${ }^{6}$ We also test for the equality of the variance-covariance matrices of $\Delta i_{t}$ and $\Delta e x_{t}$ in the subsamples (pre-ZLB and ZLB) using the log-likelihood ratio test, and we clearly reject the null hypothesis of the equality of the covariance matrices at a less than $1 \%$ significance level.

${ }^{7}$ Technically, this specific assumption would be testable if our model was overidentified with more than two regimes.
} 
Figure 2: Estimated interest rate shock $\epsilon_{t}$ and information shock $\eta_{t}$

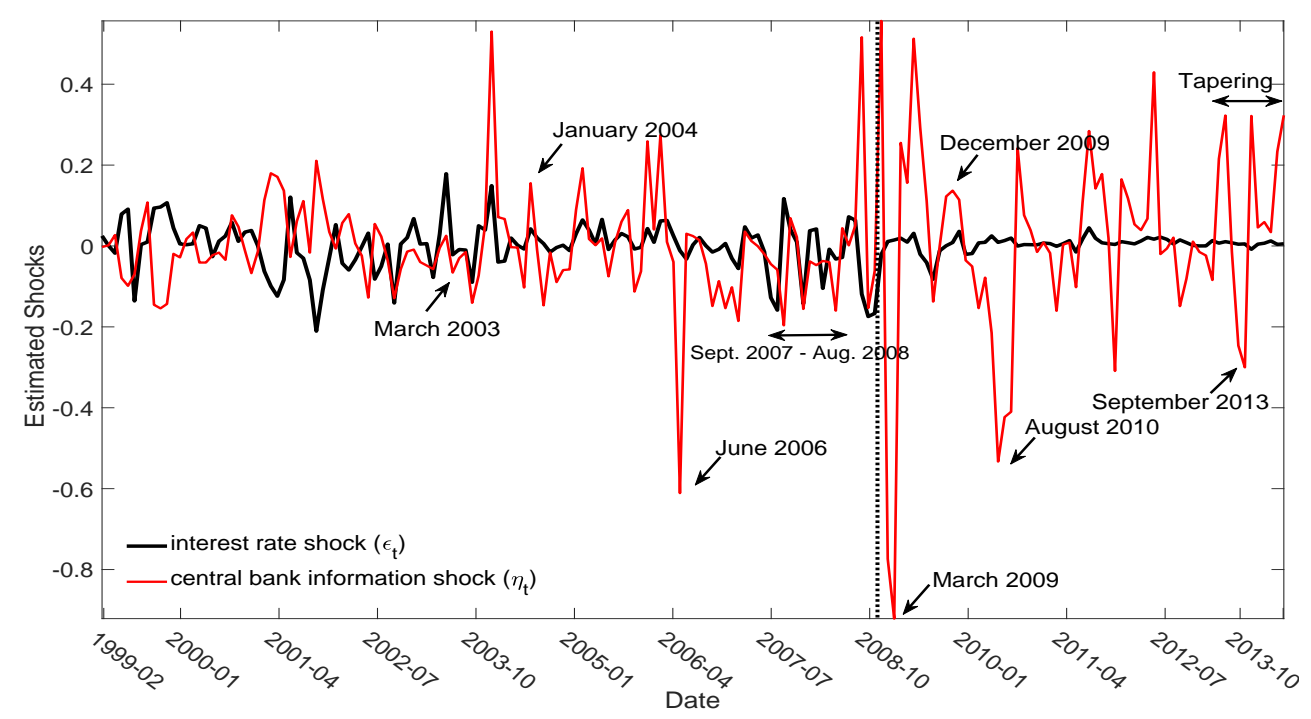

Notes: The correlation between the two estimated shocks is 0.002 . The variances in the interest rate shock series $\left(\epsilon_{t}\right)$ for the pre-ZLB and ZLB periods are 0.008 and 0.0007 , respectively. The variances in the central bank information shocks $\left(\eta_{t}\right)$ are 0.024 and 0.091 , respectively. The vertical dashed line represents December 2008.

\subsection{Narrative accounts for shock series}

We now examine the plausibility of our estimated shock series based on a historical narrative on monetary policies and announcements. Overall, the interest rate shocks are consistent with the federal funds rate changes in terms of signs. In this section, we focus more on the narrative interpretations of the central bank information shocks.

For example, the statement from the FOMC meeting on March 2003 contains no change in the target rate and negative views on the economic conditions including pessimistic words such as "disappointing" and "uncertainty". On that announcement day, the central bank information shock is negative, while the interest rate shock is almost zero.

We observe a positive spike caused by an information shock around the January 2004 announcement. Before the announcement, there were several stronger-than-expected U.S. economic data releases, but there were also concerns regarding the U.S. and China trade dispute and the U.S. current account deficit at the time. A positive information shock measured on that meeting day shows that private agents perceived the policy announcement of keeping the target rate unchanged as representing the central bank's optimistic view regarding future economic conditions.

The negative spike in the information shock series in June 2006 reflects that the contractionary monetary policy announced on that meeting day was a weaker policy response to the economic status than the economic agents expected and signaled a pessimistic view of future economic conditions. In the minutes for that FOMC meeting, monetary policy makers also noticed that private 
agents interpreted the contents from previous FOMC meeting announcements and the comments by FOMC policy makers as a higher likelihood of policy tightening, and the exchange rate appreciated over the inter-meeting period. In contrast to the dollar appreciation before the policy announcement, the dollar depreciated around the FOMC announcement, and the central bank information shock was negative. Before the ZLB period, from September 2007 to August 2008, policy announcements included continued decreases in the target rate and concerns about financial market and housing market conditions. Especially, statements repeatedly addressed that the pace of economic expansion will likely slow in the near term and that recent developments increased the uncertainty surrounding the outlook for economic growth. Our shock measures reflect several negative changes following policy announcements over this period.

During the ZLB period, the central bank information shock becomes more important. The most negative spike of the information shock is observed in March 2009 when the Fed stated that the FOMC would purchase specific amounts of both agency debt and mortgage-backed securities additionally. ${ }^{8}$ The policy announcement also stated that the economy continued to contract and predicted exceptionally low levels of the federal funds rate for an extended period. In another QE1 announcement in December 2009, the central bank information shock was positive due to an announcement that the FOMC decided to gradually slow the pace of treasury purchases, which may have provided a positive signal about the economic recovery. For the meetings in August and September 2010 related to the QE2 announcements, the central bank information shocks were negative. Announcements related to tapering generate overall positive information shocks, implying that private agents update their expectations of future economic conditions in a positive way.

In general, a central bank information shock does not occur for all QE and Operation Twist (OT) announcements in the same manner; for some QE and OT announcements, the central bank information shock is muted or positive. ${ }^{9}$ In addition, even without specific forward guidance, QE rounds, and OT announcements, our central bank information shock reacts significantly to monetary policy announcements during the ZLB period. For example, in September 2013, the central bank information shock was negative due to the central bank's pessimistic view on the pace of the economic recovery and financial conditions.

\subsection{Comparison with shock measures in the literature}

Before we employ our identified shocks for further analyses, we provide a quick comparison of our shock series with monetary policy and central bank information shocks in the literature, including Gertler and Karadi (2015), Nakamura and Steinsson (2018), Miranda-Agrippino and Ricco (2020), Jarociński and Karadi (2020), and Rogers et al. (2018). Our approach complements the previous

\footnotetext{
${ }^{8}$ The announcement is considered as one of announcements of the first round of quantitative easing (QE1): “... will purchase up to an additional $\$ 750$ billion of agency mortgage-backed securities with a total of $\$ 1.25$ trillion, up to $\$ 100$ billion agency debt this year with a total of $\$ 200$ billion and up to $\$ 300$ billion longer-term Treasury securities over the next six months."

${ }^{9}$ Cieslak and Schrimpf (2019) show that QE1 announcements trigger both monetary and non-monetary policy shocks, while the effect of other unconventional monetary policy packages is mild or muted.
} 
Table 2: Correlation with shocks in the previous literature

\begin{tabular}{ccccccccc}
\hline \hline & NS & GK & MR & Target & Forward & Asset & JK-MP & JK-CBI \\
INT shock & $0.96^{* * *}$ & $0.72^{* * *}$ & $0.37^{* * *}$ & $0.66^{* * *}$ & $0.76^{* * *}$ & -0.16 & $0.29^{* * *}$ & 0.12 \\
CBI shock & $0.21^{* *}$ & -0.03 & -0.03 & 0.02 & $0.25^{* * *}$ & $0.72^{* * *}$ & 0.09 & $-0.22^{* *}$ \\
\hline \hline
\end{tabular}

$* p<0.05,{ }^{* *} p<0.01,{ }^{* * *} p<0.001$

Notes: The benchmark shocks are our identified shock series, INT shock $\left(\epsilon_{t}\right)$ and $C B I$ shock $\left(\eta_{t}\right)$ estimated from equations (1) and (2), respectively. $N S$ refers to the policy news shock of Nakamura and Steinsson (2018). MR refers the monetary policy shock purging information components in Miranda-Agrippino and Ricco (2020). Target, Forward and Asset refer to the respective shocks identified in Rogers et al. (2018). JK-MP and JK-CBI, respectively, denote the monetary policy and central bank information shocks from Jarociński and Karadi (2020). All shock series are available from $1999 \mathrm{~m} 2-2014 \mathrm{~m} 4$, except the Asset shock series, which is only available after $2008 \mathrm{~m} 10$. All shock series are provided publicly by the authors.

literature on the central bank information effect with two distinguishable features. First, we focus on the high-frequency exchange rate that generates amplified responses around FOMC announcements after the financial crisis. Second, our identification approach using the heteroskedasticity observed in high-frequency financial data differs from previous identification approaches. Gertler and Karadi (2015) use a high-frequency surprise in the three-month ahead futures rate (FF3) measured within a 30-minute window of the FOMC announcements as an external instrument in their VAR estimation. Nakamura and Steinsson (2018) also consider high-frequency surprises around FOMC announcements in the current month Federal Funds futures rate, the Federal Funds futures rate immediately following the next FOMC meeting, and two-, three- and four-quarter-ahead Eurodollar futures and consider the first principal component of those surprises as a policy news shock. They then show that a policy news shock includes the responses of private agents to monetary policies and the central bank's private information. Miranda-Agrippino and Ricco (2020) provide a monetary policy shock purging central bank information components by regressing FF3 on Greenbook forecasts and its own lags. Jarociński and Karadi (2020) identify monetary policy and central bank information shocks using high frequency FF3 and S\&P 500 surprises around monetary policy announcements and imposing a sign restriction. Cieslak and Schrimpf (2019) consider interest rate futures with various maturities and the S\&P 500 and impose a sign restriction and monotonicity restrictions on the yield curve to measure the monetary policy and non-monetary policy news embedded in monetary policy communications. Contrary to Nakamura and Steinsson (2018), Miranda-Agrippino and Ricco (2020), and Jarociński and Karadi (2020), the focus of Rogers et al. (2018) is not the existence of a central bank information component in high-frequency surprises, but rather the focus is the identification of target interest rate, forward guidance, and large-scale asset purchases shocks, similar to Swanson (2017).

Table 2 shows the correlations between our shock measures and other shock series in the previous literature. Overall, our interest rate shock measure (INT shock) is well correlated with a policy news shock measure $(N S)$, target federal funds rate shock (Target), forward guidance shock (Forward), the monetary policy shock robust to the central bank information component $(M R)$, 
and the monetary policy shock in Jarociński and Karadi (2020) (JK-MP). Thus, our interest rate shock measure is in line with previous shock series designed to capture the interest rate changes only. Importantly, the interest rate shock measure is not significantly correlated with the central bank information shock ( $J K-C B I)$ and the asset purchase shock (Asset).

In contrast to the interest rate shock, our central bank information shock ( $C B I$ shock) is not significantly correlated with the high-frequency three-month-ahead federal futures surprise $(G K)$, the monetary policy shock without the information component $(M R)$, the target interest rate shock (Target), and the monetary policy shock in Jarociński and Karadi (2020) (JK-CBI). This is encouraging since the information shock should not include the interest rate components. The information shock is correlated with the forward guidance (Forward) and the asset purchase (Asset) shocks. This is sensible since the introduction of forward guidance and asset purchases often went hand in hand with the news. However, as we have stressed in the narrative analysis of our information shock measure, the sign of the measure can differ from the monetary stimulus and depends on the information in the FOMC statements.

We note that our information shock ( $C B I$ shock) is negatively correlated with the central bank information shock in Jarociński and Karadi (2020) (JK-CBI) to a certain degree. This can be induced by various differences between our approach and theirs, different high-frequency data series and different identification schemes. First, while we base our shock measure on the presence of heteroskedasticity, changes in the volatility are not clearly observed in the three-month-ahead federal funds future (FF3) and S\&P 500 surprises used in Jarociński and Karadi (2020). Second, their approach imposes a sign restriction that forces the interest rate to move in the same direction as the stock return change for a central bank information shock. Our identification approach, however, allows for the interest rate to move in the same or opposite direction as the changes in the exchange rate, and this feature could generate a mild negative correlation between two information shock measures. Nevertheless, many of the empirical findings in the following section are in line with the findings of Jarociński and Karadi (2020).

In the next section, we employ both identified structural shock series, the interest rate and the central bank information shock series, in proxy VAR models to investigate the effects of each shock series on the economy.

\section{The effects of interest rate and information shocks}

In this section, we start by describing the dataset and by establishing our proxy VAR model. Then, we compute the impulse responses to the identified interest rate and to the central bank information shock and discuss how the identified shocks influence the economy. 


\subsection{Data and VAR model}

We employ the external instruments in a proxy VAR similar to Gertler and Karadi (2015), which is a variation of the methodology developed by Stock and Watson (2012), Mertens and Ravn (2013), and more recently Stock and Watson (2018). As in Gertler and Karadi (2015), we consider U.S. monthly data on a variety of economic and financial variables over the period from July 1979 to April 2014. ${ }^{10}$ The endogenous variables in our VAR model are the one-year government securities rate $\left(i_{t}\right)$, the log consumer price index $\left(p_{t}\right)$, the log industrial production $\left(x_{t}\right)$, and the excess bond premium $\left(e b p_{t}\right)$ provided by Gilchrist and Zakrajšek (2012). In addition, we consider the five-year and, alternatively, the ten-year interest rates to represent the long-term interest rate $\left(l t_{t}\right)$. Furthermore, we include the log U.S. dollar narrow nominal effective exchange rate $\left(N E E R_{t}\right)$ in our VAR model. ${ }^{11}$ For the baseline VAR model, log CPI and log IP are detrended using the one-sided Hodrick-Prescott (HP) filter. ${ }^{12}$ We consider our shock series measured in the previous section as proxies of two fundamental shock components embedded in monetary policy announcements, interest rate shocks and information shocks, respectively, and conduct a VAR estimation with external instruments. ${ }^{13}$ In each case, we use the common sample between the VAR innovations and the external instruments to estimate the contemporaneous responses of variables to the shock of interest. Basically, identification with an external instrument involves regressing the estimated reduced-form innovations onto the instrument since reduced-form innovations are linear combinations of fundamental shocks in our VAR specification. As a baseline estimation, we consider a VAR with 12 lags following Gertler and Karadi (2015) and Miranda-Agrippino and Ricco $(2020) \cdot{ }^{14}$

To be confident that a weak instrument problem is not present, we conduct an $F$-test following Stock and Watson (2012). The $F$-statistic obtained by regressing the residuals of the exchange rate on changes in the exchange rate around monetary policy announcements is 15.3. This is well above the threshold (10) suggested in Stock and Watson (2012). More details on the proxy VAR specification are provided in the Appendix.

\footnotetext{
${ }^{10}$ We choose the starting point to coincide with the beginning of Paul Volcker's tenure as Federal Reserve Chair and the ending point to match the policy news shock measured by Nakamura and Steinsson (2018).

${ }^{11}$ Except for the excess bond premium index, all time series used in our VAR analysis are obtained from the St. Louis Federal Reserve Economic Data (https://fred.stlouisfed.org/).

${ }^{12}$ Both variables have a clear upward trend, but the other variables do not have such clear trends. As a robustness check, we also consider linear and quadratic detrending methods for both CPI and IP, respectively, and obtain consistent results.

${ }^{13}$ The proxy variables for interest rate and central bank information shocks are available for 123 observations on FOMC announcement dates from February 1999 to April 2014. We transform the observations on FOMC announcements into monthly series by taking into account the dates of the FOMC meetings, as in Gertler and Karadi (2015). More specifically, we accumulate all shocks at a daily frequency, obtain the average for each month, and then take the difference among months.

${ }^{14}$ We obtain overall consistent results with a VAR specification with different lag lengths, less (8 or 10) or more (14) lags.
} 


\subsection{Impulse response analysis}

We compute the impulse response function of the VAR model for interest rate shocks and information shocks. Figure 3 shows the impulse responses after an interest rate shock and the $68 \%$ confidence intervals produced by bootstrapping. Figure 4 shows the responses after a central bank information shock. ${ }^{15}$ Both shocks are scaled in such a way that the effective exchange rate appreciates by one percent point. In response to an interest rate shock, the one-year interest rate increases, and industrial production and the consumer price index decrease. Furthermore, the excess bond premium increases, which is in line with the results of Gertler and Karadi (2015). After the significant increase in the one-year rate, the response becomes negative, which is also the case for the five-year interest rate.

Figure 3: Impulse responses of the variables to an interest rate shock
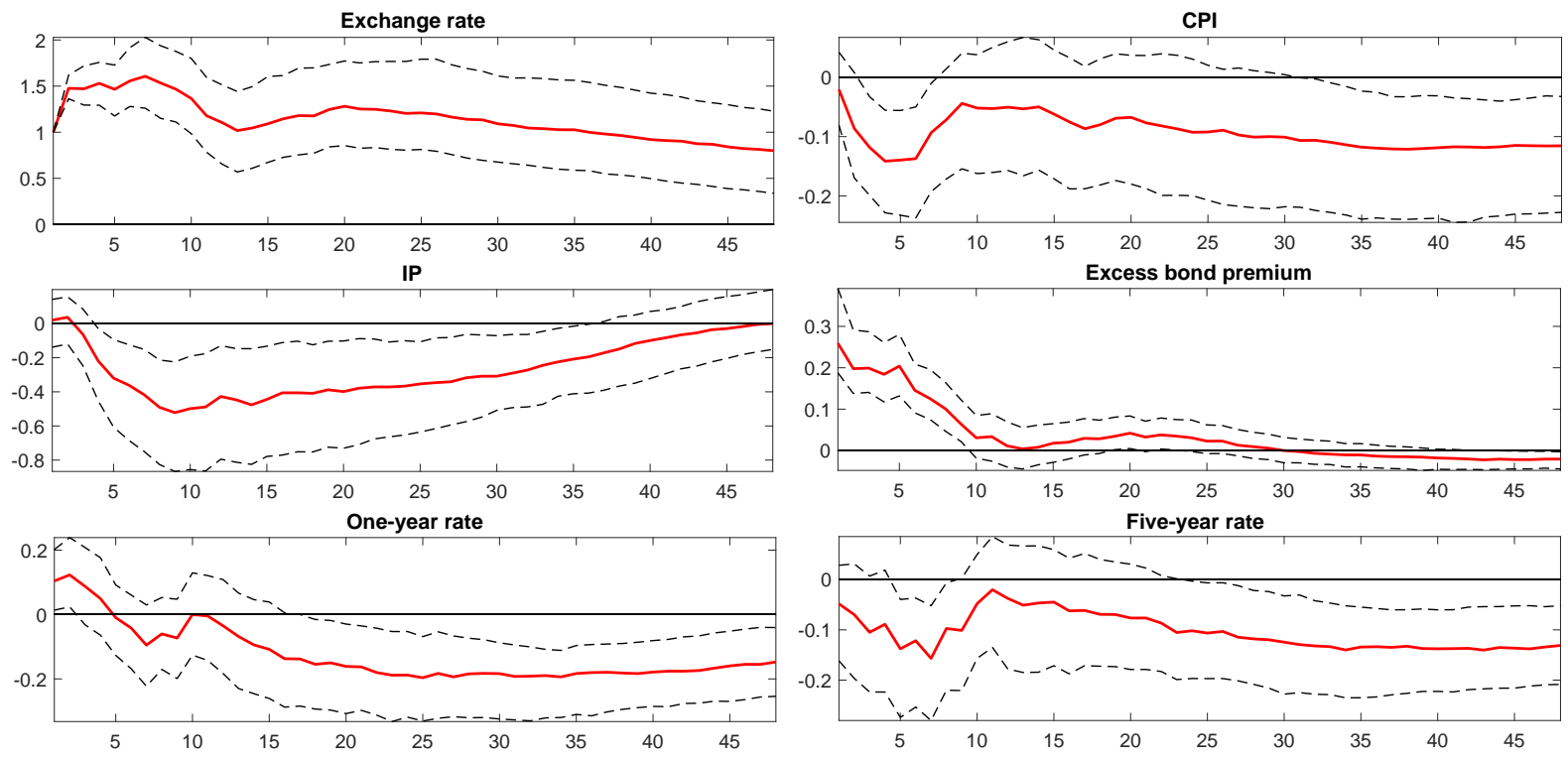

Notes: The figure represents the impulse responses of the log effective exchange rate, log CPI times 100, $\log$ IP times 100, EBP, and short- and long-term interest rates to a restrictive interest rate shock over the subsequent 48 months. The dashed lines represent the $68 \%$ confidence intervals produced by bootstrapping 500 times.

An information shock, which leads to one percent point appreciation, is (partially) expansionary. Industrial production increases. The consumer price index and the excess bond premium decrease after the information shock. The one-year rate and the five-year rate both increase. ${ }^{16}$ These

\footnotetext{
${ }^{15}$ Our identified interest rate and information shocks are estimated from equations (1) and (2). The generated regressor issue can be handled by implementing resampled changes in exchange and interest rates in the original bootstrap process, i.e., the double bootstrapping procedure suggested in Kilian (1998). The generated regressor issue may not change the results of our following analyses significantly since our identified shock measures are robust to mildly misspecified heteroskedasticity.

${ }^{16}$ As discussed in Bu et al. (2019), the industrial production index that is constructed by the Federal Reserve Board staff is one possible source of the central bank's private information. We also estimate the model with monthly
} 
impulse responses are in line with the analysis of Nakamura and Steinsson (2018), who model a central bank information shock as the central bank revealing information about the path of the natural real interest rate. Consequently, even after an increase in interest rates, inflation falls and output growth increases. Our finding is also in line with an interpretation through the lens of the model put forward by Melosi (2016). In his model, firms rely on a policy signal to infer non-policy shocks.

Figure 4: Impulse responses of variables to a central bank information shock
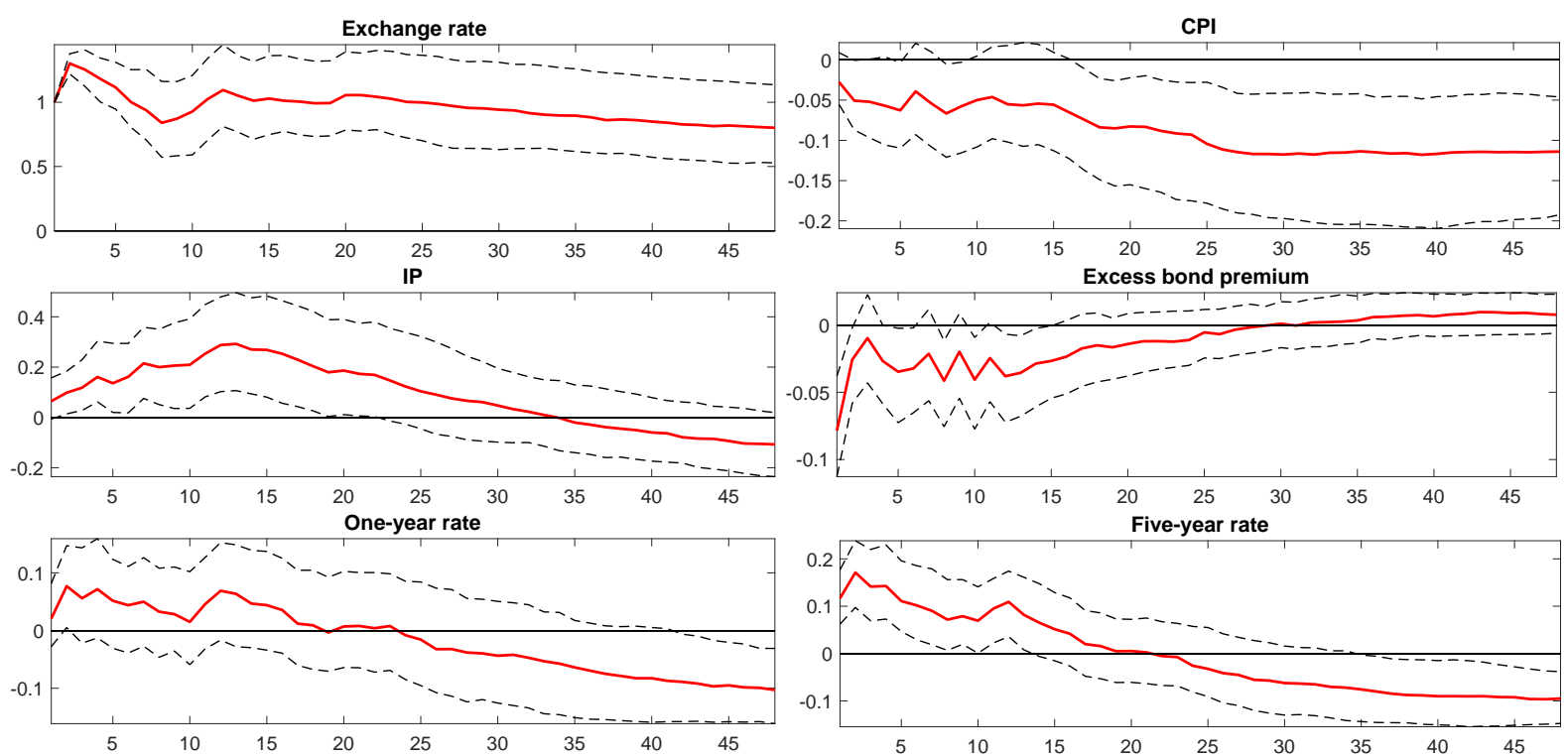

Notes: The figure represents the impulse responses of the log effective exchange rate, log CPI times 100, $\log$ IP times 100, EBP, and short- and long-term interest rates to a positive information shock over the subsequent 48 months. The dashed lines represent the $68 \%$ confidence intervals produced by bootstrapping 500 times.

The estimation results we present for the monetary interest rate and the information shocks align well with the findings of Jarociński and Karadi (2020). The authors find that a contractionary interest rate shock leads to a decrease in GDP and the GDP deflator and an increase in the excess bond premium, while a positive central bank information shock leads to an increase in GDP and the GDP deflator and to a decrease in the excess bond premium.

Our results are overall consistent with the findings from the previous literature on the effects of central bank information shocks. The price level response in our analysis, however, shows that our identified information shocks are distinguishable from those in Miranda-Agrippino and Ricco (2020) and Jarociński and Karadi (2020); the price level increases with a central bank information shock in their works but decreases with a positive information shock in our work. The distinguishable price level responses to a central bank information shock partially are in line with the negative

GDP and the GDP deflator that are interpolated following Stock and Watson (2010). Using the interpolated GDP and GDP deflator, a positive information shock induces an increase in GDP and a decrease in the GDP deflator. 
correlation between our central bank information shock and their shock that is described in Section 2.4. This is possibly related to the question regarding what kind of central bank information is revealed to the public. Jarociński and Karadi (2020) impose additional identification restrictions to separate central bank's demand and supply shock components and show that a positive central bank information on supply increases output and decreases the price level. In contrast to a demand side central bank information, however, a supply side information shock generates overall unclear responses in the interest rate, stock prices and excess bond premium in their work. Specifically, our impulse responses to a central bank information shock are consistent with the findings from the literature on technology news shocks (see Barsky and Sims (2011), Barsky et al. (2014), MirandaAgrippino et al. (2019), and Kurmann and Sims (2020), among others). A positive technology news shock changes private agents' expectations of current and future economic conditions before the realization of technological progress and induces an increase in output and decreases in the price level and excess bond premium, as shown in Figure 4.

\subsection{Robustness of the estimation results}

All of our previous results are based on the full sample analysis with the assumption that the effects of conventional monetary policy and information shocks on the economy are time-invariant. One might wonder if the effects of both shocks are different depending on the sample period. Here, we investigate whether the effects of the shocks are different for two subsample periods, pre-ZLB and ZLB periods. Using the interest rate and central bank information shocks identified in Section 2, we conduct VAR estimations for the subsamples. From the subsample analysis, we conclude that the impacts of interest rate and information shocks do not depend much on whether the economy is at the ZLB. Figures 5-8 in the Appendix show the responses to interest rate and information shocks for the subsample periods. For both pre-ZLB and ZLB periods, information shocks generate similar responses in the economic and financial variables. Interest rate shocks during the pre-ZLB period generate impulse responses that are consistent with the findings for the full sample. During the ZLB period, interest rate shocks are ineffective, and as we expect, they generate only insignificant impulse responses. ${ }^{17}$

Finally, we repeat the subsample analysis with the conventional interest rate and information shocks from our measured monetary policy shocks excluding the peak of the financial crisis. Abnormal behaviors in financial markets during financial crises are well known, and it may be questionable whether this abnormality mainly drives our estimation findings. We exclude FOMC announcement dates during the peak of the financial crisis from July 2008 to August 2009. We obtain overall similar results to the original subsample analysis.

\footnotetext{
${ }^{17}$ For the shorter time span for the subsample analysis, we consider 6 lags in the VARs. Considering more lags generates similar responses.
} 


\section{Conclusions}

In this paper, we have estimated the effects of an interest rate shock and a central bank information shock on the economy. We identify the two shocks using changes in interest rate futures and effective exchange rates around Federal Reserve announcements. Changes in the exchange rate are suitable for two reasons. First, in line with Rosa (2011), we observe that the exchange rate is especially sensitive to central bank announcements. Second, while the volatility of changes in interest rate futures considerably declines after the Federal Funds Rate reached the zero lower bound, the volatility of the exchange rate changes around monetary announcements increased.

We employ heteroskedasticity in both time series to identify an interest rate shock and a central bank information shock. Using them as proxies in a VAR model, we find that a contractionary interest rate shock appreciates the dollar, increases the excess bond premium, and leads to a decline in prices and output, while a positive information shock appreciates the dollar, decreases prices and the excess bond premium, and increases output. 


\section{References}

Andrade, P., Ferroni, F., 2018. Delphic and Odyssean Monetary Policy Shocks: Evidence from the Euro Area. Working Paper Series WP-2018-12, Federal Reserve Bank of Chicago.

Barakchian, S. M., Crowe, C., 2013. Monetary Policy Matters: Evidence from New Shocks Data. Journal of Monetary Economics 60 (8), 950-966.

Barsky, R. B., Basu, S., Lee, K., 2014. Whither News Shocks? NBER Macroeconomics Annual, 29, $225-264$.

Barsky, R. B., Sims, E., 2011. News Shocks and Business Cycles. Journal of Monetary Economics 58 (3), 273-289.

Bu, C. B., Rogers, J., Wu, W., 2019. A Unified Measure of Fed Monetary Policy Shocks. Finance and Economics Discussion Series 2019-043, Board of Governors of the Federal Reserve System.

Campbell, J. R., Evans, C. L., Fisher, J. D., Justiniano, A., Calomiris, C. W., Woodford, M., 2012. Macroeconomic Effects of Federal Reserve Forward Guidance. Brookings Papers on Economic Activity 43 (1), 1-80.

Campbell, J. R., Fisher, J. D., Justiniano, A., Melosi, L., 2016. Forward Guidance and Macroeconomic Outcomes Since the Financial Crisis. In: NBER Macroeconomics Annual 2016, Volume 31. University of Chicago Press.

Cieslak, A., Schrimpf, A., 2019. Non-Monetary News in Central Bank Communication. Journal of International Economics 118, 293-315.

Cochrane, J. H., Piazzesi, M., 2002. The Fed and Interest Rates - A High-Frequency Identification. American Economic Review 92 (2), 90-95.

Faust, J., Rogers, J. H., Swanson, E., Wright, J. H., 2003. Identifying the Effects of Monetary Policy Shocks on Exchange Rates Using High Frequency Data. Journal of the European Economic Association 1 (5), 1031-1057.

Faust, J., Swanson, E. T., Wright, J. H., 2004. Identifying VARS Based on High Frequency Futures Data. Journal of Monetary Economics 51 (6), 1107-1131.

Ferrari, M., Kearns, J., Schrimpf, A., 2017. Monetary Policy's Rising FX Impact in the Era of Ultra-Low Rates. BIS Working Paper No. 626.

Gertler, M., Karadi, P., 2015. Monetary Policy Surprises, Credit Costs, and Economic Activity. American Economic Journal: Macroeconomics 7 (1), 44-76.

Gilchrist, S., Zakrajšek, E., 2012. Credit Spreads and Business Cycle Fluctuations. The American Economic Review 102 (4), 1692-1720. 
Glick, R., Leduc, S., 2018. Unconventional Monetary Policy and the Dollar: Conventional Signs, Unconventional Magnitudes. International Journal of Central Banking 14 (5), 103-152.

Gürkaynak, R. S., Kara, A. H., Ksackoğlu, B., Lee, S. S., 2020. Monetary Policy Surprises and Exchange Rate Behavior. Working Paper 27819, National Bureau of Economic Research.

Gürkaynak, R. S., Sack, B. P., Swanson, E. T., 2005. Do Actions Speak Louder than Words? The Response of Asset Prices to Monetary Policy Actions and Statements. International Journal of Central Banking 1 (1), 55-93.

Hoesch, L., Rossi, B., Sekhposyan, T., 2020. Has the Information Channel of Monetary Policy Disappeared? Revisiting the Empirical Evidence. Working Paper Series 2020-08, Federal Reserve Bank of San Francisco.

Inoue, A., Rossi, B., 2019. The Effects of Conventional and Unconventional Monetary Policy on Exchange Rates. Journal of International Economics 118, 419-447.

Jarociński, M., 2019. International Spillovers of the Fed and ECB Monetary Policy Surprises. Working paper, European Central Bank.

Jarociński, M., Karadi, P., 2020. Deconstructing Monetary Policy Surprises - The Role of Information Shocks. American Economic Journal: Macroeconomics 12 (2), 1-43.

Kilian, L., 1998. Small-Sample Confidence Intervals For Impulse Response Functions. The Review of Economics and Statistics 80 (2), 218-230.

Kurmann, A., Sims, E., 2020. Revisions in Utilization-Adjusted TFP and Robust Identification of News Shocks. Review of Economics and Statistics, Forthcoming.

Kuttner, K. N., 2001. Monetary Policy Surprises and Interest Rates: Evidence from the Fed Funds Futures Market. Journal of Monetary Economics 47 (3), 523-544.

Melosi, L., 2016. Signalling Effects of Monetary Policy. The Review of Economic Studies 84 (2), 853-884.

Mertens, K., Ravn, M. O., 2013. The Dynamic Effects of Personal and Corporate Income Tax Changes in the United States. American Economic Review 103 (4), 1212-1247.

Miranda-Agrippino, S., Ricco, G., 2020. The Transmission of Monetary Policy Shocks. American Economic Journal: Macroeconomics, Forthcoming.

Miranda-Agrippino, S., Sinem, H. H., Bluwstein, K., 2019. When Creativity Strikes: News Shocks and Business Cycle Fluctuations. Staff Working Paper No. 788, Bank of England.

Nakamura, E., Steinsson, J., 2018. High-Frequency Identification of Monetary Non-Neutrality: The Information Effect. The Quarterly Journal of Economics 133 (3), 1283-1330. 
Neely, C. J., 2015. Unconventional Monetary Policy Had Large International Effects. Journal of Banking and Finance 52, 101-111.

Ramey, V., 2016. Chapter 2 - Macroeconomic Shocks and Their Propagation. Handbook of Macroeconomics 2, 71-162.

Rigobon, R., 2003. Identification Through Heteroskedasticity. The Review of Economics and Statistics $85(4), 777-792$.

Rogers, J. H., Scotti, C., Wright, J. H., 2018. Unconventional Monetary Policy and International Risk Premia. Journal of Money, Credit and Banking 50 (8), 1827-1850.

Rosa, C., 2011. The High-Frequency Response of Exchange Rates to Monetary Policy Actions and Statements. Journal of Banking and Finance 35 (2), 478-489.

Rossi, B., 2019. Identifying and Estimating the Effects of Unconventional Monetary Policy in the Data: How to Do It and What Have We Learned? Working Papers 1081, Barcelona Graduate School of Economics.

Sims, C. A., Zha, T., 2006. Were There Regime Switches in U.S. Monetary Policy? American Economic Review 96 (1), 54-81.

Söderström, U., 2001. Predicting Monetary Policy with Federal Funds Futures Prices. Journal of Futures Markets 21 (4), 377-391.

Stock, J. H., Watson, M. W., 2010. Research Memorandum.

Stock, J. H., Watson, M. W., 2012. Disentangling the Channels of the 2007-2009 Recession. Brookings Papers on Economic Activity 42 (1), 81-135.

Stock, J. H., Watson, M. W., 2018. Identification and Estimation of Dynamic Causal Effects in Macroeconomics. Economic Journal, Forthcoming.

Swanson, E. T., 2017. Measuring the Effects of Federal Reserve Forward Guidance and Asset Purchase on Financial Markets. NBER Working Papers 23311. 


\section{Appendix}

\section{Appendix A: Data Description}

For choosing the variables for the VAR, we follow Gertler and Karadi (2015) and include industrial production, the consumer price index, the one-year government bond rate, and the excess bond premium from Gilchrist and Zakrajšek (2012) and add the nominal effective exchange rate and fiveyear (ten-year) interest rate. As a robustness check, we also consider the monthly (interpolated) real gross domestic production (GDP) and GDP deflator instead of industrial production and the consumer price index. We collect the data from the St. Louis Federal Reserve Economic Data (http://fred.stlouisfed.org/), except for the excess bond premium index taken from Gilchrist and Zakrajšek $(2012)^{18}$. All endogenous variables used in the VAR estimation are available from July 1979 to April 2014.

Nominal effective exchange rate: The log U.S. dollar narrow nominal effective exchange rate (mnemonics: NNUSBIS) is used.

Industrial production: The log industrial production (INDPRO) is detrended using the one-sided Hodrick-Prescott (HP) filter.

Consumer price index: The log consumer price index (CPIAUCSL) is detrended using the one-sided Hodrick-Prescott (HP) filter.

Real GDP and GDP deflator: The quarterly GDP (GDP) and GDP deflator (USAGDPDEFQISMEI) are interpolated to monthly frequency series following Stock and Watson (2010). The monthly real GDP is calculated using the interpolated nominal GDP and GDP deflator. Both variables are log transformed and detrended using the one-sided HodrickPrescott (HP) filter.

Interest rates: The one- and five-year treasury constant maturity rates (GS1 and GS5, respectively) are used.

Regarding the monetary policy shock measures, high-frequency exchange rates and the Nakamura and Steinsson (2018) policy news shock measure are used. We also consider other monetary policy shock measures for the shock comparisons in Section 2.4, including the monetary policy shock measures from Gertler and Karadi (2015), Rogers et al. (2018), Nakamura and Steinsson (2018), Miranda-Agrippino and Ricco (2020), and Jarociński and Karadi (2020).

High-frequency exchange rates: The one-minute exchange rates for the U.S. dollar versus the Euro, the Canadian dollar, the British pound, the Swiss franc, the Japanese yen, the Australian dollar, and the Mexican peso are obtained from Olsen Financial Technologies. All exchange rate series are available from February 1, 1999, to April 31, 2014.

\footnotetext{
${ }^{18}$ The index is downloaded from https://www.aeaweb.org/articles?id=10.1257/aer.102.4.1692.
} 


\section{Appendix B: A VAR with an External Instrument}

Various econometric models with an external instrumental variable have been used for monetary policy analyses. Especially, the vector autoregression, local projection, and hybrid models with an external instrument are widely studied in terms of their asymptotic and finite sample properties (see, e.g. Ramey (2016) and Stock and Watson (2018)). We investigate the impacts of interest rate and central bank information shocks on the economy using a VAR with an external instrument. As an alternative, local projection with an instrument also delivers consistent estimates, but it is less efficient compared to the VAR with an instrument. In addition, by considering a VAR specification, we can estimate the model coefficients with longer historical macro data available from 1979:7 to 2014:4. The variables used in the baseline VAR model are collected in a vector $\left(Y_{t}\right)$ :

$$
Y_{t}=\left[\begin{array}{llllll}
N E E R_{t} & i_{t} & x_{t} & p_{t} & e b p_{t} & l t_{t}
\end{array}\right]^{\prime} .
$$

where $N E E R$ denotes the U.S. narrow nominal effective exchange rate, $i_{t}$ is the one-year government securities rate, $x_{t}$ is the log industrial production, $p_{t}$ is the log consumer price index, $e b p_{t}$ is the excess bond premium provided by Gilchrist and Zakrajšek (2012), and $l t_{t}$ is the five-year interest rate. Our VAR model with 6 endogenous variables and 12 lags is given by

$$
y_{t}=K_{0}+K(L) y_{t-1}+\nu_{t}, \quad \nu_{t} \sim \text { i.i.d. }\left(0, \Sigma_{\nu}\right),
$$

where $K(L)$ denotes the lagged reduced-form VAR model coefficients, and $K_{0}$ is the intercept term. $\nu_{t}$ denotes the $n \times 1$ vector of reduced-form errors with the corresponding variance-covariance matrix $\Sigma_{\nu}$. The reduced-form errors $\nu_{t}$ are related to the structural errors $u_{t}$ as follows:

$$
\nu_{t}=S u_{t}, \quad u_{t} \sim \text { i.i.d. }(0, I)
$$

Here, $S$ is a square matrix with the dimension equal to the number of endogenous variables. The reduced-form exchange rate shock $\nu_{t}^{e x}$, the first element of $\nu_{t}$ in our setup, is a linear combination of fundamental shocks $u_{t}$.

To identify the effects of an interest rate shock and the an information shock on the variables in our VAR model, we first obtain the estimates of the reduced-form residuals $\hat{\nu}_{t}$. We denote the reduced-form shocks that correspond to the exchange rate as $\hat{\nu}_{t}^{e x}$. In the second step, we regress this reduced-form shock ${\hat{\nu_{t}}}^{e x}$ on our proxy variables $\epsilon_{t}$ and $\eta_{t}$, respectively. This yields the fitted value $\tilde{\nu}_{t}^{e x, i}, i \in\{\epsilon, \eta\}$ as a variation in $\hat{\nu}_{t}^{e x}$ that only captures the changes induced by a monetary policy shock $\epsilon_{t}$ or an information shock $\eta_{t}$.

In the final step, we identify the elements of interest in $S$ by regressing the remaining reducedform errors $\left(\hat{\nu}_{t}^{q}\right)$ on $\tilde{\nu}_{t}^{e x, i}$. More precisely, we let $s^{1}$ be the first element of the first column of matrix $S$ capturing the response of the exchange rate to interest rate and central bank information shocks. Furthermore, we let $s^{q}$ be remaining elements of the first column of $S$ that describe the responses of other variables to our shock measure. Thus, the effects of $\tilde{\nu}_{t}^{e x, \epsilon}$ on the other variables are estimated 
by regressing other reduced-form residuals on $\tilde{\nu}_{t}^{e x, i}$ :

$$
\hat{\nu}_{t}^{q}=\frac{s^{q}}{s^{1}} \tilde{\nu}_{t}^{e x, i}+\zeta_{t}, \quad i \in\{\epsilon, \eta\},
$$

where $\zeta_{t}$ comprises all other structural shocks, which are orthogonal to $\epsilon_{t}$ and $\eta_{t}$. The estimated coefficients from above regressions represent how other macro variables respond to interest rate and central bank information shocks relative to the response of the exchange rate $\left(s^{1}\right)$ to those shocks. 


\section{Appendix C: Additional Figures}

Figure 5: Impulse responses of the variables to an interest rate shock: pre-ZLB
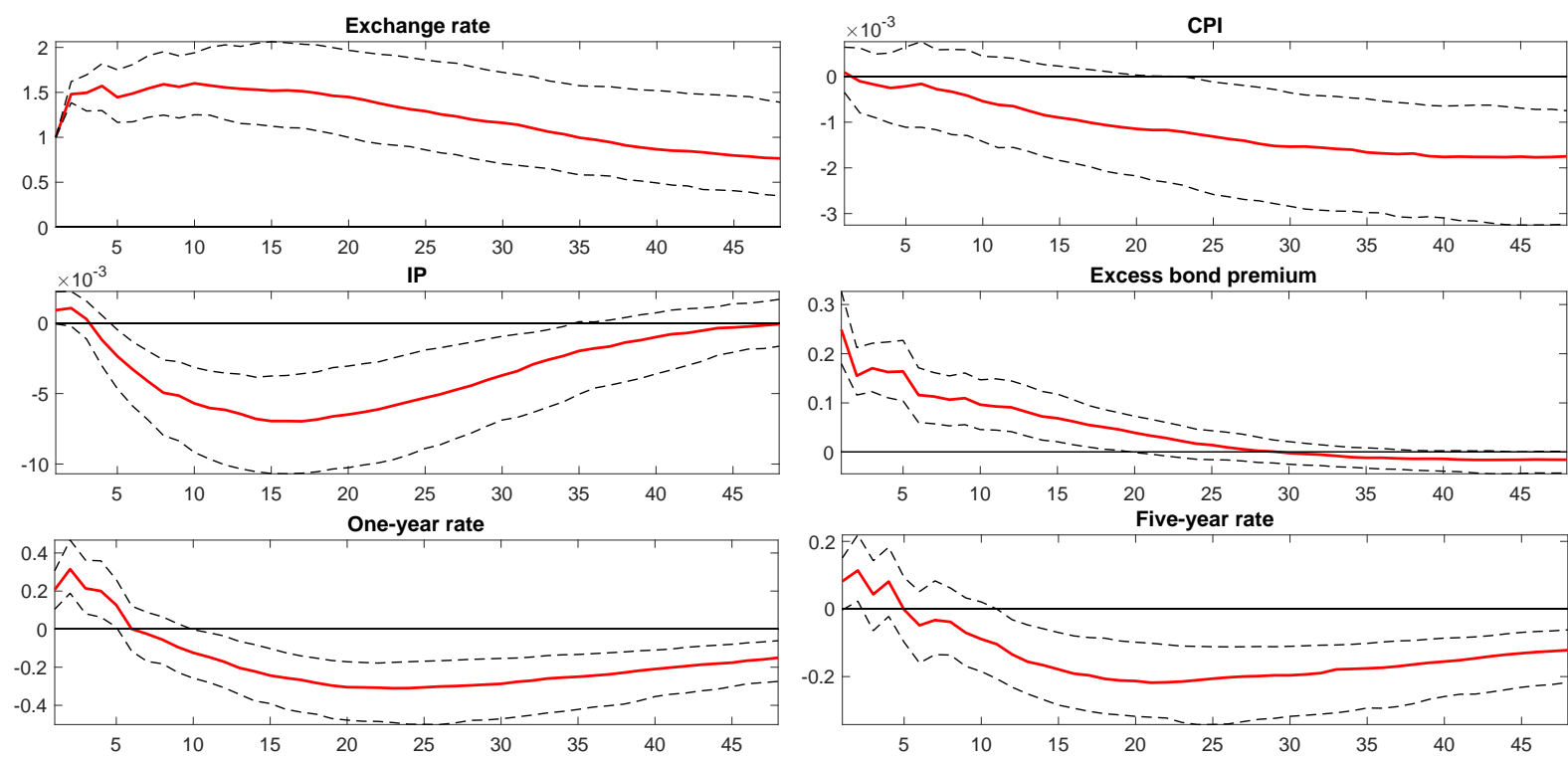

Notes: The figure represents the impulse responses of the log effective exchange rate, log CPI times 100, log IP times, EBP, and short- and long-term interest rates to a restrictive interest rate shock in the pre-ZLB period. The dashed lines represent the $68 \%$ confidence intervals produced by bootstrapping 500 times. 
Figure 6: Impulse responses of the variables to an interest rate shock: ZLB
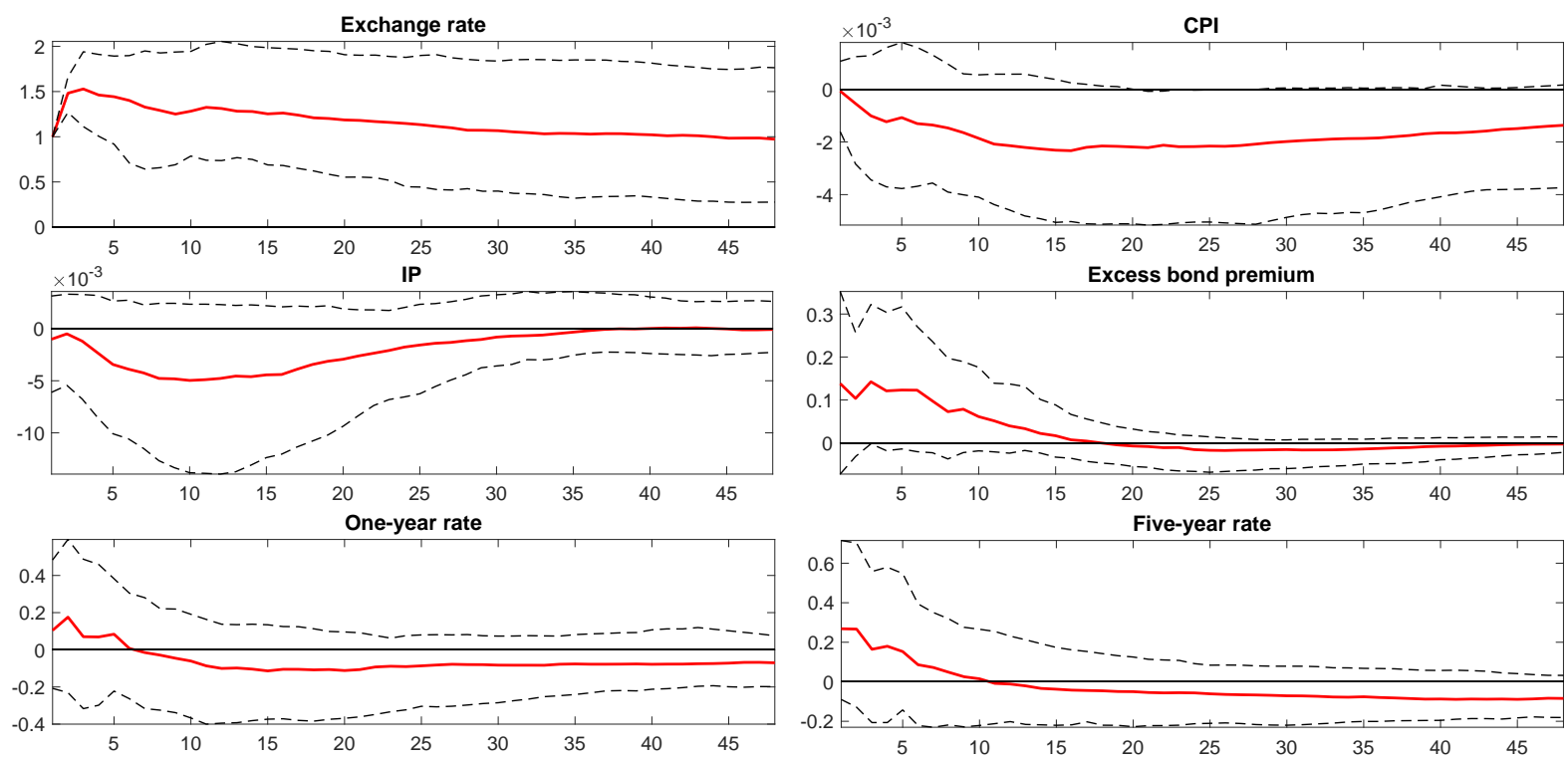

Notes: The figure represents the impulse responses of the log effective exchange rate, log CPI times 100, log IP times 100, EBP, and short- and long-term interest rates to a restrictive interest rate shock in the ZLB period. The dashed lines represent the $68 \%$ confidence intervals produced by bootstrapping 500 times.

Figure 7: Impulse responses of the variables to a central bank information shock: pre-ZLB
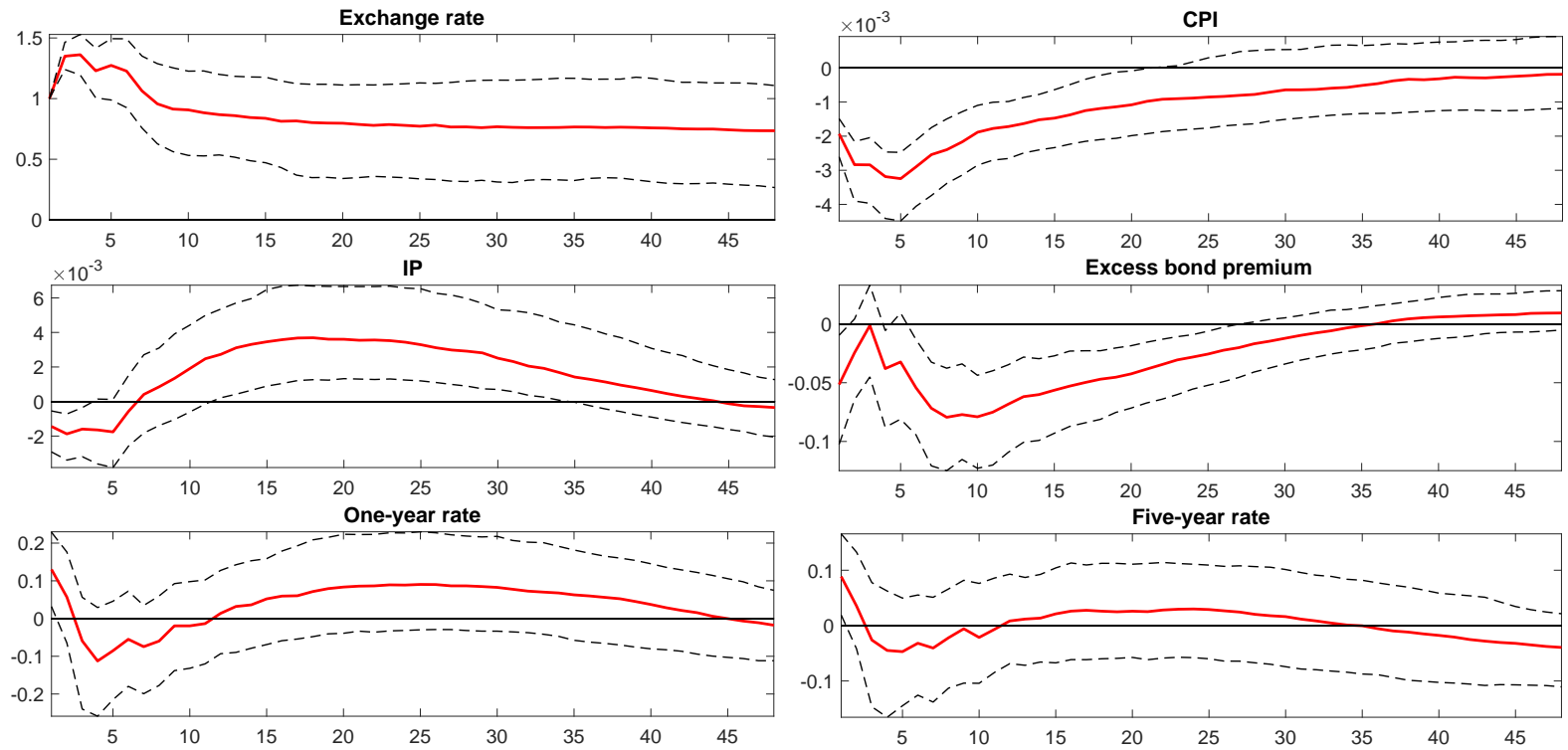

Notes: The figure represents the impulse responses of the log effective exchange rate, log CPI times 100, $\log$ IP times 100, EBP, and short- and long-term interest rates to a positive central bank information shock in the pre-ZLB period. The dashed lines represent the $68 \%$ confidence intervals produced by bootstrapping 500 times. 
Figure 8: Impulse responses of the variables to a central bank information shock: ZLB
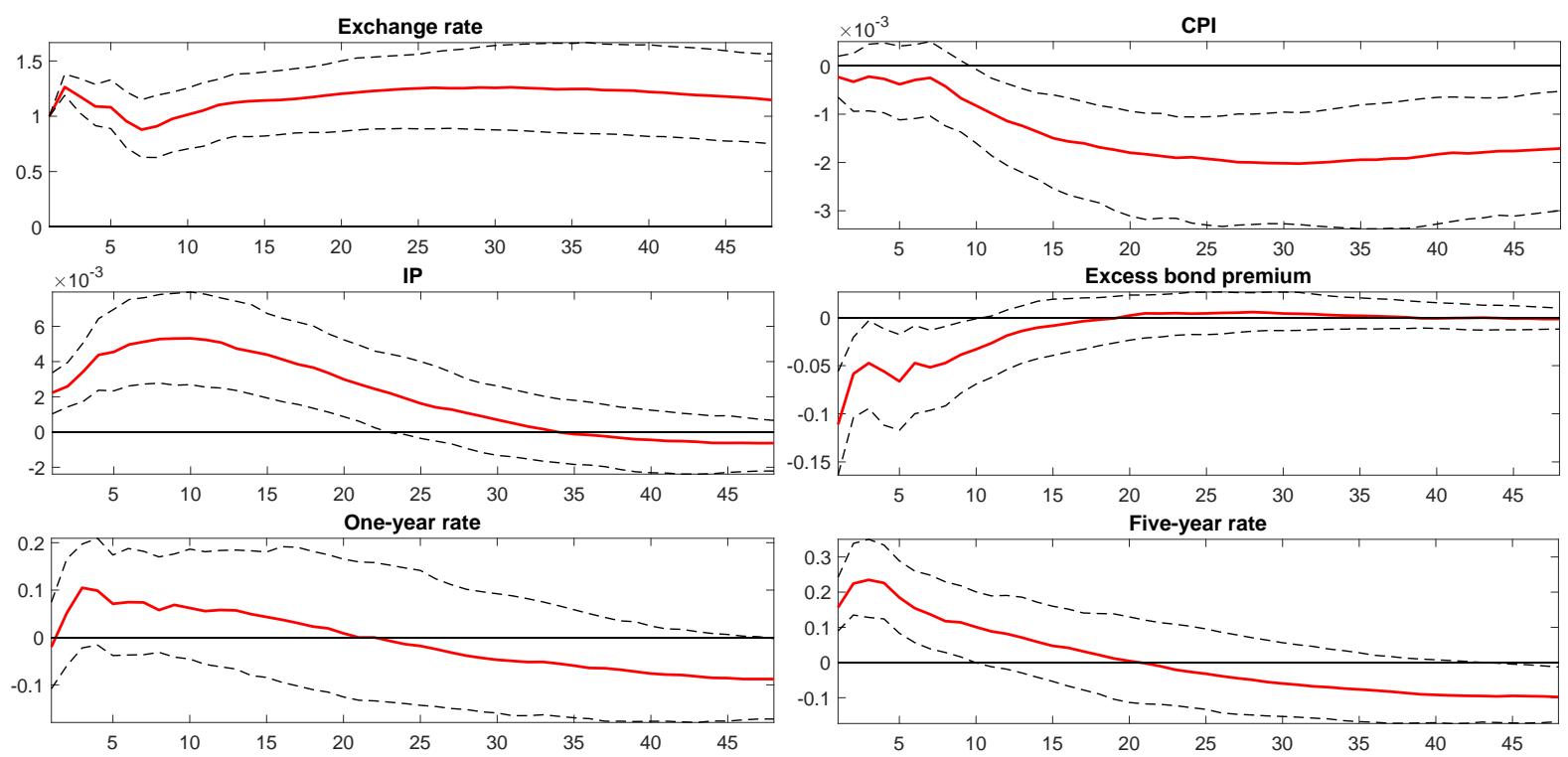

Notes: The figure represents impulse responses of the log exchange rate, log CPI times 100, log IP times 100, EBP, and short- and long-term interest rates to a positive central bank information shock in the ZLB period. The dashed lines represent the $68 \%$ confidence intervals produced by bootstrapping 500 times. 